\title{
Promotion of Community-based Disaster Reduction Activity through Hands-on Training in Sri Lanka
}

\author{
Tetsushi Kurita ${ }^{1}$, Makoto IkedA ${ }^{2}$, Koji SuZukI ${ }^{2}$ and Sisira R. N. ColombagE ${ }^{3}$ \\ ${ }^{1}$ Tokyo Electric Power Services Co., Ltd. \\ (formerly of the Asian Disaster Reduction Center) \\ ${ }^{2}$ Asian Disaster Reduction Center \\ ${ }^{3}$ Monash University, Australia
}

(Received for 25 May., 2007 and in revised from 14 Jan, 2008)

\begin{abstract}
The number of natural disasters in Sri Lanka has increased over the last two decades. In particular, the Indian Ocean Tsunami had a disastrous impact on communities in Sri Lanka, with 4,330 deaths and 564 persons reported missing (as of 05 April 2005) in Galle District. In order to raise public awareness of various categories of citizens on disaster reduction, the capacity building project at all community levels starting from the grass-roots level was carried out in Galle District. The initial process started from the process of trainer's training, the so-called District Workshop, and the outcome made the participants trainers in their localities and they repeated the same exercise to educate their communities in Community Workshops. The progress of the project was followed up by Japanese experts. A total of 102 Community Workshops were held in the immediate phase after the District Workshop. The practical session consists of a Community-based Hazard Mapping program of which the results were used to identify disaster vulnerable areas in community neighborhood by the participants.
\end{abstract}

\section{INTRODUCTION}

\subsection{Background and Issues}

The amount of damage caused by natural disasters in Sri Lanka has been increasing over the last 20 years (e.g. National Disaster Management Centre, 2004). Deforestation of watersheds, massive wastewater volumes caused by haphazard land use, and intense monsoon rains are all contributing to the greater incidence of floods and landslides. The massive flooding that occurred in May 2003 in Galle District (a regional city of about 910,000 located $100 \mathrm{~km}$ south of Colombo) caused 16 fatalities and affected more than 22,000 people. A UN Disaster Assessment and Coordination Team (UNDAC) was dispatched to the disasterstricken area (UNOCHA, 2003) following this disaster. Later, the Indian Ocean Tsunami of December 2004 decimated the coastal communities of Sri Lanka. In Galle District, 4,330 people perished, and 564 were missing. More than 7,032 homes sustained major damage (according to figures published by Galle District on April 5, 2005). Galle District was one of the most heavily damaged regions in Sri Lanka.

The enormity of the damage caused by the Indian Ocean Tsunami is attributed to external forces, that is, the massive size of the tsunami, as well as internal forces, that is, a lack of disaster reduction capacity in the affected countries. Several careful studies of the region have been conducted since the disaster, and this article presents an overview of the results and a summary of the issues that need to be addressed.
Given the severity of the damage caused by the Indian Ocean Tsunami, UNESCO-IOC (Intergovernmental Oceanographic Commission) sent international expert teams to the 16 affected nations to conduct assessments of local tsunami warnings and natural disaster management systems (UNESCO, 2005 a \& b). The results of this study were compiled into a highly detailed report. The findings show that the Sri Lankan authorities and the international expert team are currently aware of the following issues. First, they confirm that what is needed to strengthen the disaster reduction capacity in the affected countries is a comprehensive risk management strategy, as well as community-based efforts to raise disaster awareness and provide disaster reduction education to local residents. They also point out the need for modules to educate people regarding the hazards of tsunamis and other natural disasters in general as well as their long-term impacts. The Sri Lankan national government recognizes the need to promote activities (including community workshops) aimed at raising disaster awareness at all levels, from the government to the local community.

The expert teams made the following suggestions. To raise the awareness of local residents, it is important to involve people at all levels, including the government (central and regional), civic organizations, and other important relevant institutions. To raise the level of awareness at the local level, particularly of the residents of remote areas, training needs to be provided to people who can serve as teachers in citizen education programs. Because of the lack of disaster reduction education materials in the affected countries, technologies and materials already in use in nations and 
international institutions with advanced disaster reduction capabilities need to be transferred to these countries.

A questionnaire-format attitude survey conducted among residents, children, and government officials in the tsunami-stricken regions of Galle District in March 2005 by Kurita et al. (Kurita et al., 2005 \& Kurita et al., 2006) confirmed the lack of knowledge of natural disasters among local residents and the need to raise disaster awareness. A survey of government officials revealed the need for community-based disaster reduction education.

From its position as an institution involved in providing support for disaster management systems in developing nations, JICA (2006) also showed that there are technical and funding limits to what can be achieved by "hard" infrastructural efforts, such as the construction of dams and embankments, in the area of disaster reduction in developing countries. It showed that efforts need to be made to strengthen the disaster reduction capacity of communities through the introduction of "soft" policy measures, including outreach among residents and disaster reduction education in schools. After the 2004 tsunami, JICA conducted a community uplift project in northeastern Sri Lanka. JICA takes an approach that emphasizes this kind of support from the perspective of "human security.”

In Japan, several local governments, including Kobe City (Inaba, 2007), Wakayama Prefecture (Tabata, 2007), Kochi Prefecture (Nakagawa, 2007), Kagawa Prefecture (Miyamoto, 2007) and Tokushima Prefecture (Otsubo, 2007), have been conducting programs promoting community workshops on disaster reduction. Community-based hazard mapping is a main component of these workshops. These programs have produced positive results. For example, workshops conducted in Marikina City, Metro-Manila, Philippines (Maki et al., 2004) enabled municipal government officials to work with Japanese experts to develop a comprehensive earthquake disaster reduction program for the city. In Sri Lanka, however, the kinds of projects mentioned above were not carried out prior to the 2004 Indian Ocean Tsunami because it had not been considered a disaster prone country.

Because strong community ties are characteristic of Sri Lankan society, conducting disaster reduction education at the grass-roots level is an extremely useful step in increasing the disaster reduction capacity of the entire country.

\subsection{Objectives}

To tackle the challenges described above, we conducted activities to raise the community disaster reduction capacity in the tsunami-affected Galle District of Sri Lanka. The objective of these activities is to raise the citizens' natural disaster awareness at various levels. We are striving to help ensure that comprehensive and continuous disaster reduction activities become firmly established in Sri Lanka by providing personnel training to citizens at the grass-roots level.

\subsection{Activity Outline}

Under this project, we conducted activities to promote community disaster reduction education through community-based hazard mapping. This method is one in which residents, government officials, and experts walk around the city together identifying problem areas for disaster reduction, and then develop policies for addressing those problems through in-depth discussions. The pro- ject is comprised of two stages: (1) the District Workshop (trainers' training) and (2) the Community Workshop (residents' education).

Minimizing damage requires sustained efforts and can only be achieved when the government, experts, and citizens work together based on a strong awareness of the issues. Thus, disaster reduction education is not a one-time isolated event, but requires the construction of a system under which the authorities can take the initiative to continue conducting disaster reduction education even after externally supported projects end. This project helps support the creation of such a system by transferring technical methods to Galle District and developing support systems for the necessary activities.

\subsection{Anticipated Results}

This project is intended to contribute to the creation of an environment in which people will gain a deeper and more accurate understanding of natural disasters, and in which disaster awareness will be improved from the grass-roots level. This will then likely lead to reductions in fatalities and property losses caused by future natural disasters. The workshops will teach people how to handle disasters both before and after they strike. Thus, advance measures will help eliminate the vulnerabilities of communities, and disaster preparations will help increase their disaster response capacity. This project will help residents, government officials, and experts become accustomed to discussing issues of disaster reduction and will promote greater risk communication.

In terms of international support for the disaster reduction field, this project will allow Japan to transfer the know-how it has gained from its vast disaster reduction experience to Sri Lanka and will allow Sri Lanka to share technologies based on Japan's experience.

\section{CURRENT ANALYSIS OF DISASTER MAN- AGEMENT SYSTEMS}

\subsection{Government Level}

Because of the massive damage caused by the 2004 Indian Ocean Tsunami, the government of Sri Lanka passed the Sri Lanka Disaster Management Act (No. 13, May 2005) to establish a government framework for disaster reduction. Based on this law, the government also established the National Council for Disaster Management (NCDM), to be headed by the president, to serve as a venue for the comprehensive discussion of disaster reduction policies at the national level. The Ministry of Disaster Management and Human Rights was established in November 2005 to serve as the body that will implement the policies formulated by the NCDM. The institution at the core of the Ministry of Disaster Management and Human Rights is called the Disaster Management Centre and it manages the district disaster management coordinators assigned to each district.

In 2005, the Disaster Management Centre created a roadmap for the short-term, mid-term, and long-term periods covering the next 10 years, which lays out a comprehensive strategy for building a safe Sri Lanka (Disaster Management Centre, 2005). This roadmap is comprised of the following seven key points: (1) Policy, institutional mandates and institutional development, (2) 
hazard, vulnerability, and risk assessment, (3) multi-hazard early warning systems, (4) preparedness and response plans, (5) mitigation and integration of disaster risk reduction into development planning, (6) community-based disaster risk management, and (7) public awareness, education, and training. The overall content of the roadmap is appropriate, but some cost estimations of the programs it contains remain unclear. Also, because difficulties can be expected to arise in securing budget allocations, there are still doubts as to whether the disaster policies will actually be promoted as planned.

Since little thought has been given to disaster reduction in Sri Lanka thus far, there are virtually no personnel who specialize in natural disaster reduction. The military or police generally handle emergency situations, including natural disasters, after they occur. For this reason, military personnel have been assigned to serve as the director general and district disaster management coordinators of the newly established Disaster Management Centre. However, the secretary serving as the top administrator of the Ministry of Disaster Management and Human Rights is a civilian bureaucrat.

\subsection{Community Level}

Because the government's disaster reduction systems were inadequate, it is easy to imagine the lack of community-level disaster response organizations and activities. However, Sri Lankan communities are characterized by strong interpersonal ties, and certainly have the key ingredients for developing community-wide approaches to disaster reduction.

On the other hand, Sri Lankan society is comprised of three communities (Sinhala, Tamil, and Muslim) with various ethnic, religious, and historical backgrounds. The Sinhala are the majority ethnic group throughout the country, while the Tamil and Muslims are minority groups. Southern Sri Lanka, which includes Galle District where this project was conducted, has an overwhelming majority of Sinahala, and thus has virtually no conflict between communities. The northern and northeastern regions, however, are home to Tamil militants, the Liberation Tigers of Tamil Elam (LTTE), who repeatedly clash with government forces over their desire for independence. Such ethnic conflicts present obstacles to emergency response activities, and exacerbate disaster-related problems. On October 18, 2006, while this project was underway, LTTE cadres used five boats to conduct suicide bombings at Dakshina Naval Base in the city of Galle. They were repulsed by naval troops (The Island newspaper, 2006). A curfew was imposed throughout Galle District for about one week after this terrorist attack, and conditions prevented us from holding Community Workshops during that time. Later, the situation improved and things returned pretty much to normal.

\section{PROJECT DESIGN}

In designing this project, we could not simply take the methods used in Japan and transplant them directly into the Sri Lankan environment. Instead, we took the specific conditions of Sri Lanka into account and devised methods that would work best in that context. For example, in Japan, evacuations are carried out based on detailed forecasting or early warnings issued by the Japan Meteorological Agency (JMA) and/or municipalities. In Sri Lanka, however, it is unlikely that residents would receive such information from any institutions. We therefore selected an evacuation process that would require residents to make their own decision regarding the need to evacuate.

The project was conducted for one year, from April 2006 to March 2007. We were careful to create a system that would allow local residents to learn the methods of disaster reduction during that period, and then to continue their own activities beyond the project's end. The following is a detailed description of the project.

\subsection{Structure}

Fig. 1 shows the overall flow of the project. The primary theme of the project was to conduct community disaster reduction education using community-based hazard mapping by groups that include local residents. This is a method in which residents, government officials, and experts walk around the city together identifying problem areas, and then work together to develop policies for addressing those problems through in-depth discussions. The project was implemented in two stages: (1) the District Workshop, in which local government officials were trained to be trainers (train-

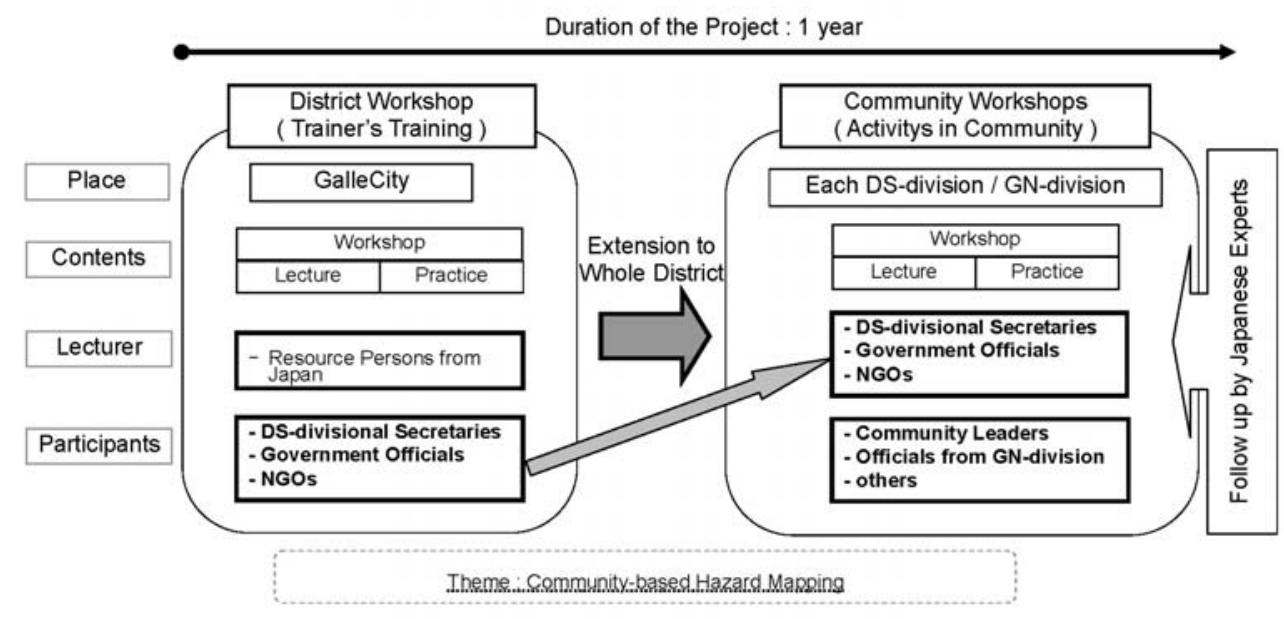

Fig. 1 Project Flow and Overview 
ers' training), and (2) Community Workshops held in the areas of jurisdiction of those trainers, who then taught what they had learned to members of their local communities.

About 100 people, including local government officials and NGO staff members, were trained at the district-level workshop. Over the course of three days, participants learned methods of disaster reduction education from lectures and hands-on training provided by Japanese experts. Sri Lankan experts also gave lectures on natural disasters in Sri Lanka. The training was held at the Management Development Training Institute in Galle District. The final step of the workshop was to create an action plan for the workshops that would be conducted during the second stage of the project, at the community level. We prepared manuals in Sinhalese, the official language of Sri Lanka, regarding "community-based hazard mapping," the primary theme of this project, and distributed them to all participants.

During the second stage, the participants in the District Workshop became trainers who taught one-day courses on community-based hazard mapping for community leaders and the general public. The outputs of these workshops are (1) a community-based hazard map, (2) a summary identifying the problems found, proposed countermeasures, and the authority responsible for implementing the solution, and (3) an action plan for the future. An average of five workshops were held in all 19 DS-divisions of Galle District (more workshops were held in more densely populated areas), for a total of 100 workshops. During the project period, we used a system in which locally hired staff provided full-time support for our activities. Japanese experts visited Sri Lanka several times over the course of the project to monitor progress and offer guidance. We attended the first two Community Workshops along with all of the District Workshop attendees. We conducted the pilot lessons in a manner consistent with the District Workshop, identified and corrected problems in the implementation of the Community Workshop, and took steps to prevent problems from arising in future activities. Each Community Workshop produced a hazard map that was created by the participants of each community, and these maps can be used in various disaster reduction activities in the future.

\subsection{Community-Based Hazard Mapping}

The procedures for creating a community-based hazard map, the primary theme of this project, are as follows.

(1) Participants are divided into groups by residential neighborhood. Roles are assigned to the members of each group, such as leader, note-taker, photographer, cartographer, and presenter. When this activity is conducted in Japan, participants use blank neighborhood maps as their base map, but such detailed maps are not available for some regions of Sri Lanka. Thus, the participants in this project had to draw their own maps. Hence the need for a cartographer who could sketch a map of the target area.

(2) The group walks around the target area and identifies dangers, evacuation areas, and evacuation routes based on local hazards (tsunamis, floods, landslides, etc.). They identify both the positive disaster reduction efforts and the problems in the area. They take pictures of such positive and negative points and important landmarks.

(3) After returning to the workshop venue, the group discuss- es the information they collected and decide what information to include on their hazard map. They draw their map on Simili paper, and then add the components they previously deemed to be important. They also attach some of the photos that were taken.

(4) They create a list of the problems they identified during their city walk, identify means of addressing those problems, and clarify who is responsible for implementing solutions.

(5) Based on these activities, they then create an action plan indicating what measures to take to reduce damage in the target area the next time a disaster occurs.

(6) Finally, all the participants gather together to listen to each group give a report on its outputs (a communitybased hazard map, summary identifying the problems found, proposed countermeasures, and the authority responsible for implementing the solution, and an action plan for the future). All of the workshop participants, including citizens, government officials, and experts discuss the results presented by each group.

\subsection{Project Implementation System}

This project was primarily implemented by the Galle District Secretariat, with technical support provided by the Asian Disaster Reduction Center. Thus, under the instruction of the district secretary, each DS-divisional secretary held Community Workshops in various regions. Fig. 2 shows the project implementation structure for Galle District. District disaster management coordinators and NGOs support projects managed by the district government.

\subsection{Project Evaluation Methods}

The following two methods were used to evaluate this project. First, trainee feedback about the workshop was quantitatively examined by conducting a questionnaire survey among the participants of the District and Community Workshops. Second, a final evaluation session was conducted in March 2007, after the project had ended, where we listened to input from officials of the Galle District government, which had implemented the project. We performed an overall evaluation of the project by combining these two methods.

\section{PROJECT IMPLEMENTATION}

\subsection{District Workshop}

The District Workshop, which served as the session to train the trainers, was held over three days, from April 18-20 2006, at the training center in Wakwella in Galle District. Of the 100 people from the Galle District government and NGOs who were invited to attend, a total of 87 people participated in the workshop. On the first day, participants listened to lectures about disaster reduction by experts from both Japan and Sri Lanka. On the second and third days, they identified community problems by participating in the community-based hazard mapping process, and learned how to facilitate discussions among government officials, experts, and citizens and how to develop countermeasures. The 87 participants were divided into 10 groups, and they surveyed the central areas of Galle that were affected by the tsunami (Pettigala Watta, China 


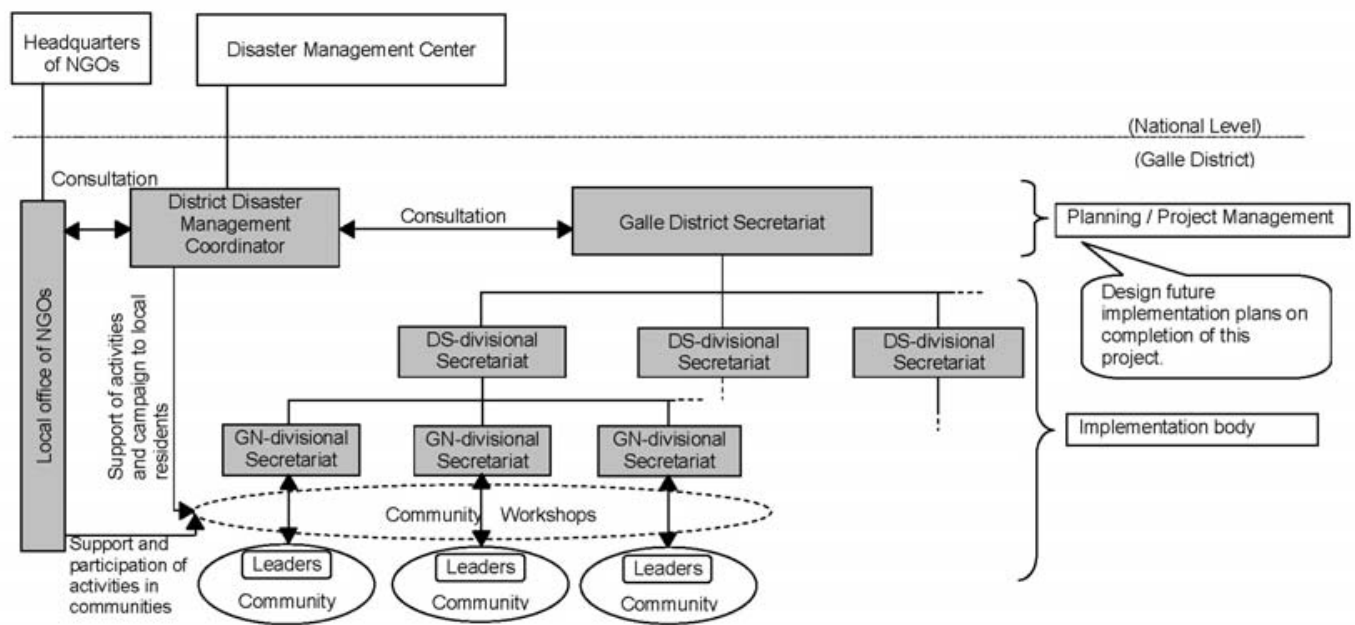

Participants of the District Workshop

Fig. 2 Project Implementation Structure for Galle District.

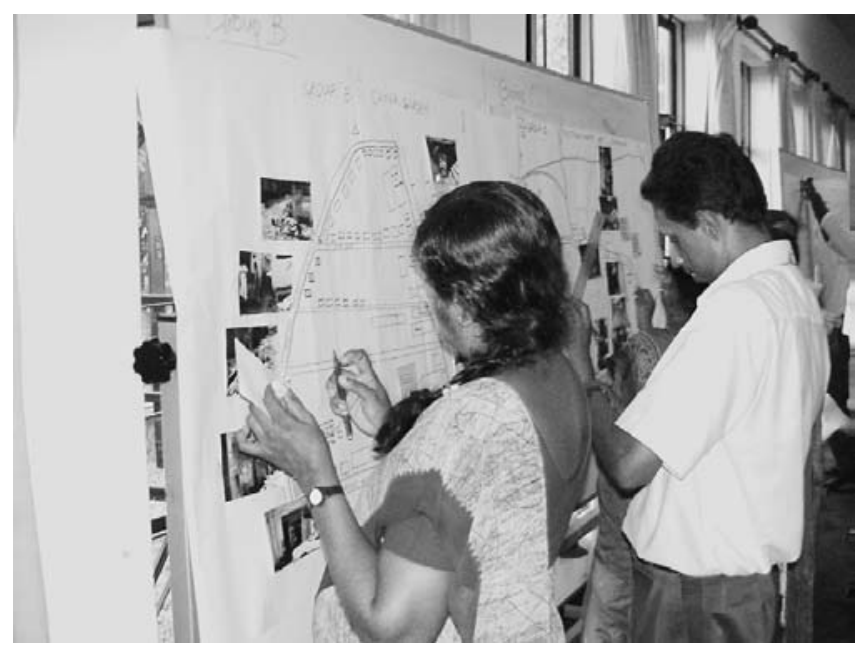

Fig. 3 District Workshop Participants Create Hazard Maps.

Garden, Kaluwella, and Fort). Each of the groups included a Japanese specialist. As a result of the participants' active engagement, they were able to create well-designed community-based hazard maps (Fig. 3). When the groups gave their presentations, they did an excellent job of summarizing their findings and giving complete reports on their activities and maps (Fig. 4). In their action plans for the future, they were told to identify (1) the participants that should attend Community Workshops, (2) the locus of responsibility for community activities, (3) a general time schedule, (4) ultimate goals, and (5) requests for the district government or supporting organizations.

A questionnaire survey conducted at the end of the District Workshop yielded a total of 71 valid responses. Of these, 50 were from male respondents and 21 were from females. The average age of the respondents was 46.6 years. Fig. 5 shows the aggregated results of the survey on the content of the workshop program. It shows that $80 \%$ to $90 \%$ of participants strongly agreed or agreed with all of the statements on the questionnaire. This indicates that most participants were satisfied with the workshop content. On two of the statements ("This training solved problems that I had

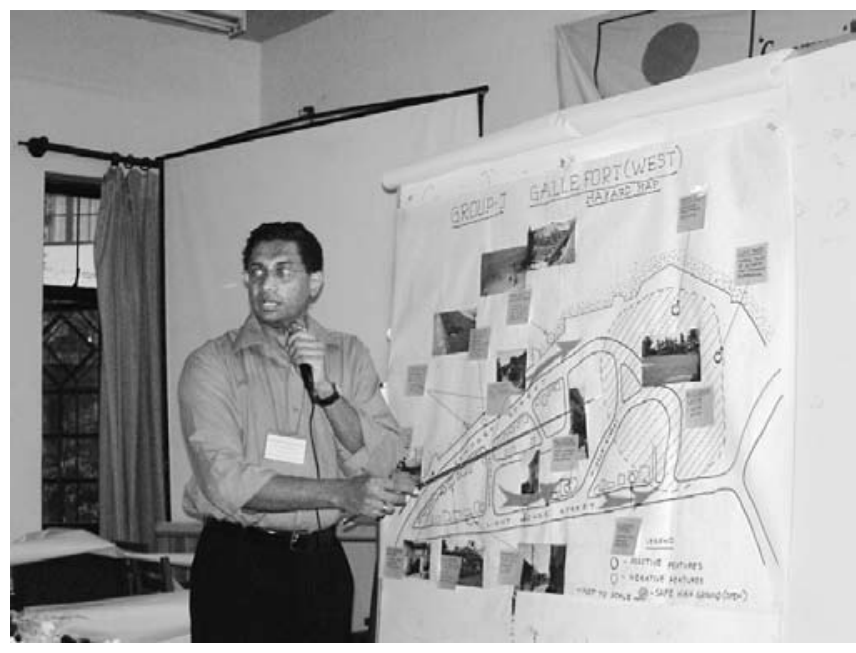

Fig. 4 Presentations by District Workshop Participants.

been facing" and "I acquired new knowledge as a result of the session”), however, about $10 \%$ of the participants selected neutral responses, suggesting that there is still room to improve in this area. On a question regarding the distributed materials, as shown in Fig. 6, more than $95 \%$ of the participants indicated agreement with all of the statements, confirming that the materials were effective and useful in helping to improve the participants' understanding. Fig. 7 shows the results of the survey regarding future activities. This suggests that $90 \%$ or more of participants have a strong intent to promote these activities in Galle District. On the other hand, there appears to be some uncertainty regarding the development of activities inside and outside the district. This conclusion is drawn from the fact that respondents feel it will be difficult for them to develop the program outside the district on their own due the limited authority of local government officials.

At the same time the multiple-choice surveys shown in Figs. 5-7 were conducted, a free-response format survey was also conducted. The responses in the free-response section show that many participants had positive opinions of the workshop. The community-based hazard mapping exercise was especially highly rated. The 


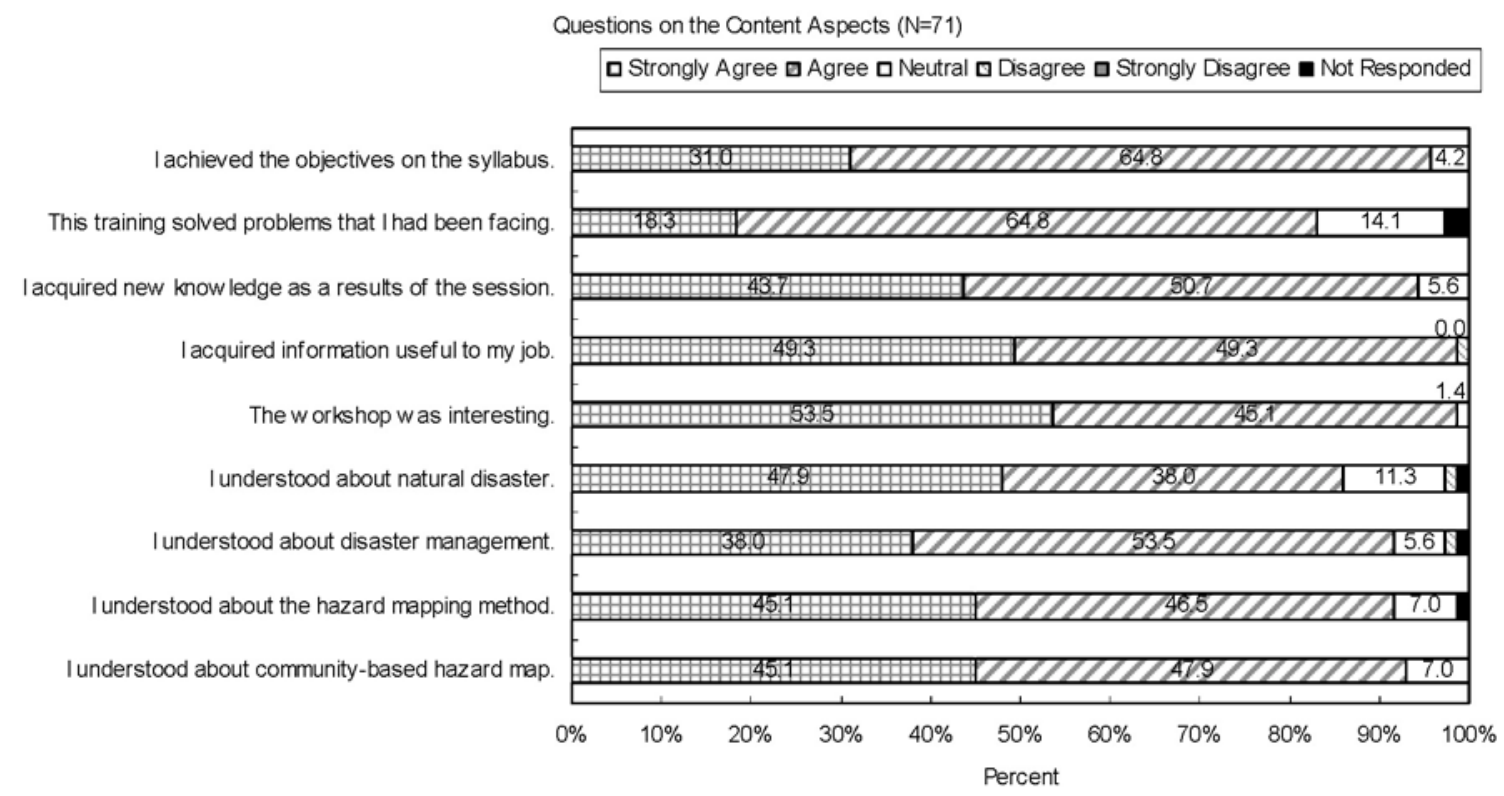

Fig. 5 Results of Survey about the Program Content Conducted among District Workshop Participants.

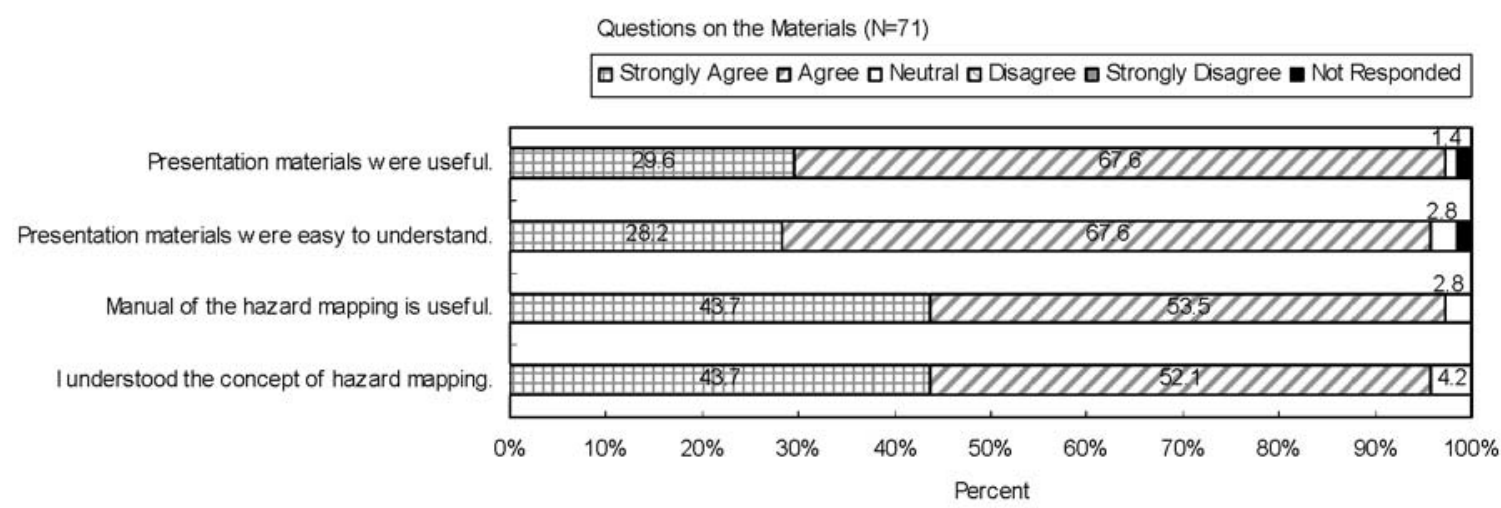

Fig. 6 Results of Survey about the Materials Distributed to District Workshop Participants.

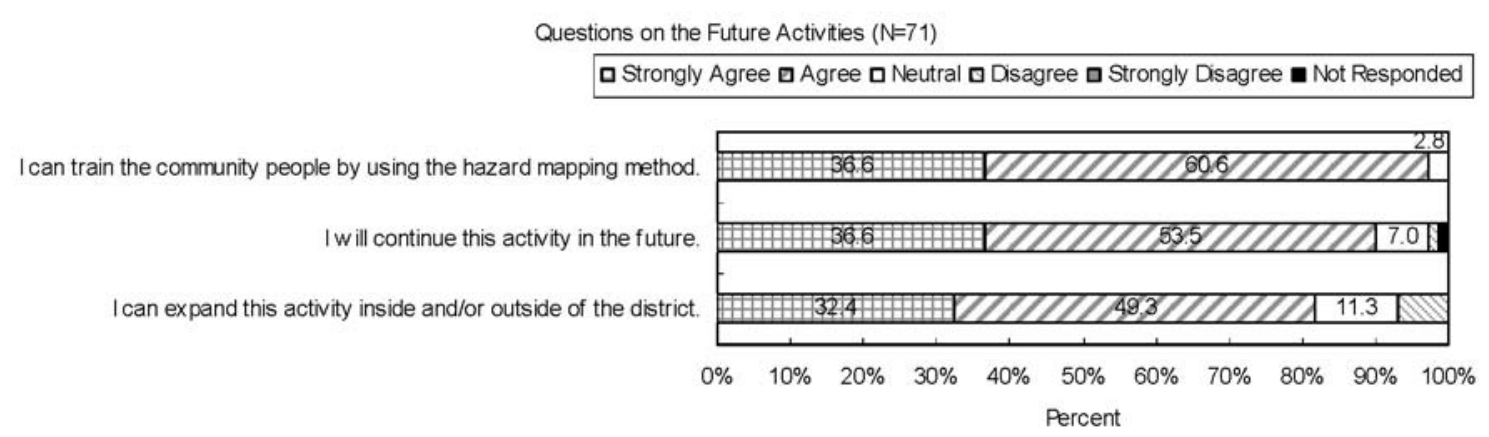

Fig. 7 Results of Survey about Future Activities Conducted among District Workshop Participants.

comments and suggestions provided by participants included (1) a desire for workshops on other topics in disaster management, (2) the need for disaster exercises in schools, and (3) the need for partnerships with relevant institutions. Several of the participants also indicated that because of Sri Lanka's inexperience with large-scale disasters, they would like to learn about the disaster management experiences of other countries through similar kinds of workshop.

\subsection{Pilot Community Workshop}

In the week following the District Workshop (the trainers' training), pilot Community Workshops were held in the two DSdivisions of Niyagama and Baddegama. The trainers in these works shops had participated in the previous District Workshop, and the attendees were community leaders and other local residents. There were 21 participants in the Niyagama Workshop on April 24 and 20 participants in the Baddegama Workshop on April 26. Fig. 8 shows the participants surveying their target areas. Fig. 


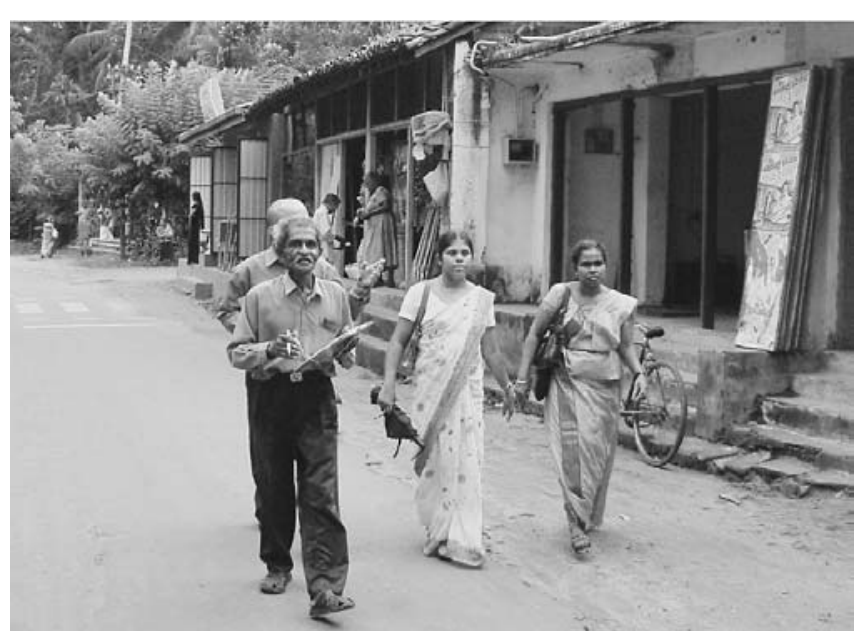

Fig. 8 Residents Take a Walking Survey of the Community During the Community Workshop.

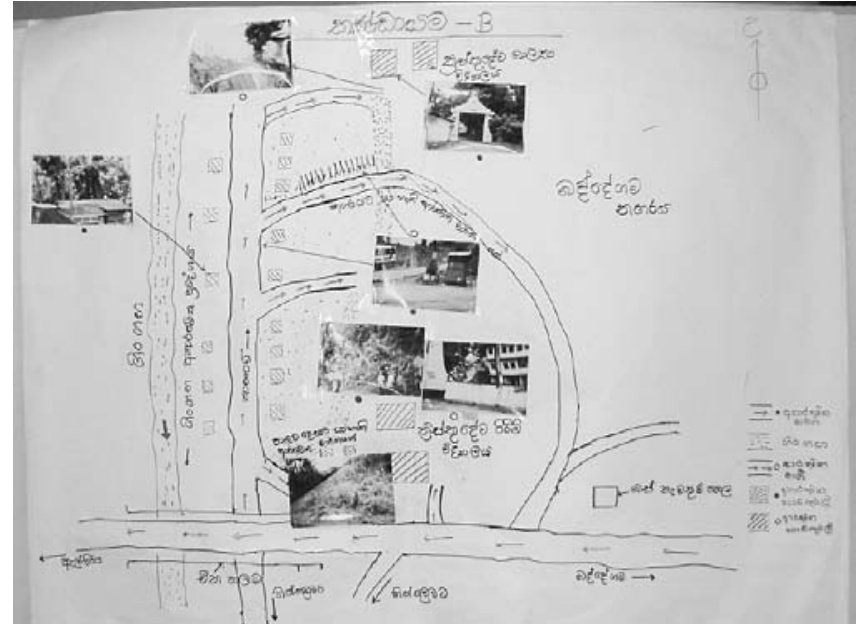

Fig. 9 Sample Hazard Map Created by Participating Residents.

Table 1 Numbers of Community Workshops Participants.

\begin{tabular}{|c|c|c|c|c|c|c|c|c|c|c|c|c|c|}
\hline \multirow{2}{*}{ DS-division } & \multicolumn{9}{|c|}{2006} & \multicolumn{3}{|c|}{2007} & \multirow{2}{*}{ Total } \\
\hline & Apr. & May. & Jun. & Jul. & Aug. & Sept. & Oct. & Nov. & Dec. & Jan. & Feb. & Mar. & \\
\hline Benthota* & - & 39 & - & 27 & - & 38 & 33 & - & 35 & - & 32 & - & 204 \\
\hline Balapitiya* & - & 33 & - & 39 & - & 35 & 32 & - & 29 & - & 32 & 32 & 232 \\
\hline Karandeniya & - & 33 & - & 33 & 33 & 30 & - & - & 31 & 31 & - & 39 & 230 \\
\hline Elpitiya & - & 28 & - & 34 & 34 & 33 & - & 31 & - & 36 & 35 & $\underline{77}$ & 308 \\
\hline Niyagama & 21 & - & 28 & 32 & 37 & - & - & 40 & - & 35 & 28 & - & 221 \\
\hline Thawalama & - & - & - & 29 & 38 & - & - & - & - & - & - & - & 67 \\
\hline Neluwa & - & 34 & - & - & 27 & - & - & - & - & - & - & - & 61 \\
\hline Nagoda & - & - & 26 & - & 34 & 33 & - & 37 & - & 31 & 38 & 29 & 228 \\
\hline Baddegama & 20 & - & 39 & - & 26 & - & - & 35 & - & - & - & 47 & 167 \\
\hline Welivitiya-Divithura & - & - & 29 & - & - & 35 & - & 35 & - & 35 & - & - & 134 \\
\hline Ambalangoda* & - & - & 38 & - & - & 33 & - & 32 & - & 40 & - & - & 143 \\
\hline Hikkaduwa* & - & - & 33 & - & - & 29 & - & 40 & 34 & - & - & 27 & 163 \\
\hline Galle Four Gravets* & - & - & - & 40 & 36 & 39 & - & - & 42 & - & - & - & 157 \\
\hline Bope-Poddala & - & - & 37 & 40 & 34 & - & 34 & - & - & 37 & $\underline{70}$ & 44 & 296 \\
\hline Akmeemana & - & - & $\underline{41}$ & - & 40 & 33 & - & - & - & - & 36 & 39 & 189 \\
\hline Yakkalamulla & - & - & 25 & 28 & - & - & - & - & 35 & - & - & - & 88 \\
\hline Imaduwa & - & 33 & - & 28 & - & 34 & - & 29 & - & 30 & - & - & 154 \\
\hline Habaraduwa* & - & 32 & - & 27 & 33 & - & 33 & 35 & - & 32 & 19 & - & 211 \\
\hline Gonapinuwala & - & - & 27 & - & - & 39 & - & - & 39 & 32 & - & - & 137 \\
\hline Total & 41 & 232 & 323 & 357 & 372 & 411 & 132 & 314 & 245 & 339 & 290 & 334 & 3,390 \\
\hline
\end{tabular}

* Coastal DS-division. Bold figures indicate the results of the pilot community workshop. Underlined figures indicate the sum total for the two workshops.

9 shows a sample of one of the hazard maps created by local citizens. In this area, flooding from the river, which flows north to south as shown along the left side of Fig. 9, is the most serious hazard for the village located to the east. In both Community Workshops, the residents accurately identified the problem areas and produced well-designed outputs (community-based hazard map, summary of problems, and an action plan).

These two pilot Community Workshops confirmed that the participants in the District Workshop were able to effectively serve as Community Workshop instructors and to guide residents on the creation of their community-based hazard maps.

\subsection{Community Workshops}

Systematic implementation of the Community Workshops in the various DS-divisions started in May. As shown in Table 1, a total of 102 Community Workshops (including the two pilot Community Workshops) were held over the course of a year, attracting 3,390 participants. This is the number of people that received direct benefit during the project implementation period, but continuation of these activities in the future is expected to extend these benefits to many more. To prevent all the workshops from being held in the same location in any given DS-division, they were held not only at government facilities, but at varying locations throughout the community, including temples. The table shows that only four workshops were held in October, fewer than in any other month. This is due to the rescheduling of all the workshops that had been planned for October because of the curfew that was imposed following the terrorist attacks mentioned above. 
Table 2 Basic Information about Community Workshop Participants $(\mathrm{N}=2,940)$.

\begin{tabular}{|c|c|c|c|c|c|c|c|c|c|c|c|}
\hline \multirow{2}{*}{ DS-division } & \multicolumn{3}{|c|}{ Gender $(\%)$} & \multicolumn{7}{|c|}{ Age $(\%)$} & \multirow{2}{*}{$\begin{array}{c}\text { Average } \\
\text { Age }\end{array}$} \\
\hline & Male & Female & N.R. & -20 & $21-30$ & $31-40$ & $41-50$ & $51-60$ & $61-$ & N.R. & \\
\hline Benthota* & 43.4 & 56.6 & 0.0 & 8.2 & 9.3 & 23.1 & 22.5 & 20.3 & 14.8 & 1.6 & 44.4 \\
\hline Balapitiya* & 51.1 & 47.2 & 1.7 & 4.4 & 11.7 & 27.2 & 27.8 & 13.9 & 7.8 & 7.2 & 41.8 \\
\hline Karandeniya & 50.5 & 49.5 & 0.0 & 14.8 & 26.0 & 20.9 & 15.3 & 14.3 & 3.1 & 5.6 & 36.7 \\
\hline Elpitiya & 37.2 & 60.9 & 1.8 & 1.8 & 14.6 & 20.1 & 24.5 & 17.2 & 15.7 & 6.2 & 45.8 \\
\hline Niyagama & 24.1 & 74.1 & 1.7 & 7.5 & 27.0 & 13.2 & 20.1 & 19.0 & 6.3 & 6.9 & 39.2 \\
\hline Thawalama & 53.4 & 44.8 & 1.7 & 22.4 & 29.3 & 13.8 & 17.2 & 8.6 & 3.4 & 5.2 & 34.0 \\
\hline Neluwa & 27.3 & 70.9 & 1.8 & 7.3 & 25.5 & 25.5 & 16.4 & 9.1 & 1.8 & 14.5 & 35.6 \\
\hline Nagoda & 31.0 & 67.5 & 1.5 & 3.5 & 17.5 & 30.0 & 28.0 & 14.5 & 2.0 & 4.5 & 39.5 \\
\hline Baddegama & 47.0 & 51.5 & 1.5 & 7.5 & 11.9 & 32.1 & 20.1 & 10.4 & 14.9 & 3.0 & 42.1 \\
\hline Welivitiya-Divithura & 26.3 & 71.9 & 1.8 & 7.9 & 19.3 & 23.7 & 17.5 & 15.8 & 7.9 & 7.9 & 40.3 \\
\hline Ambalangoda* & 48.7 & 49.6 & 1.7 & 5.0 & 16.8 & 21.8 & 16.0 & 21.8 & 16.0 & 2.5 & 44.4 \\
\hline Hikkaduwa* & 45.7 & 54.3 & 0.0 & 8.6 & 11.4 & 29.3 & 17.1 & 20.0 & 7.1 & 6.4 & 41.3 \\
\hline Galle Four Gravets* & 44.7 & 50.4 & 4.9 & 4.1 & 8.1 & 26.0 & 24.4 & 17.9 & 15.4 & 4.1 & 45.6 \\
\hline Bope-Poddala & 44.3 & 55.0 & 0.7 & 5.0 & 13.6 & 24.6 & 22.5 & 13.6 & 15.7 & 5.0 & 44.4 \\
\hline Akmeemana & 39.4 & 58.2 & 2.4 & 12.9 & 15.9 & 12.4 & 20.0 & 17.1 & 15.9 & 5.9 & 43.9 \\
\hline Yakkalamulla & 30.1 & 65.1 & 4.8 & 6.0 & 24.1 & 18.1 & 22.9 & 14.5 & 4.8 & 9.6 & 40.7 \\
\hline Imaduwa & 22.8 & 74.1 & 3.2 & 5.7 & 13.3 & 20.3 & 13.3 & 24.1 & 19.0 & 4.4 & 45.2 \\
\hline Habaraduwa* & 58.0 & 39.1 & 2.9 & 25.3 & 17.8 & 15.5 & 16.1 & 13.8 & 7.5 & 4.0 & 35.8 \\
\hline Gonapinuwala & 61.1 & 34.1 & 4.8 & 13.5 & 8.7 & 17.5 & 23.8 & 20.6 & 12.7 & 3.2 & 43.9 \\
\hline Total & 41.6 & 56.6 & 1.8 & 8.4 & 16.1 & 22.0 & 20.9 & 16.5 & 10.9 & 5.3 & 41.8 \\
\hline
\end{tabular}

* Coastal DS-division.

Also, only two workshops were held during the year in both Thawalama and Neluwa, fewer than the number held in any of the other areas. Since the goal was to hold five workshops in each DSdivision, the workshops were clearly not adequately implemented in these locations. Since both of these regions are located in inland areas on high plateaus, with relatively little danger of being affected by tsunamis, floods, or landslides, there was little interest in disaster reduction among residents. The government officials therefore took a passive approach to holding workshops in these areas. Because it is difficult to spark interest in the topics addressed by this project in these kinds of low risk areas, other methods of conducting disaster reduction education need to be developed for such regions. In addition, personnel changes in the DS-divisional secretary in both DS-divisions led to the replacement of those personnel while the project was underway. The appointment of new personnel who had not participated in the District Workshop also contributed to the reduced number of Community Workshops.

Basic information about the participants in each DS-division is provided in Table 2. A breakdown by gender shows that female participants slightly outnumbered male participants. This trend was especially noticeable in the four areas of Niyagama, Neluwa, Welivitiya-Divithura, and Imaduwa. The age breakdown of participants in all regions shows that the distribution of generations is well balanced. A further breakdown within each DS-division shows that Thawalama and Habaraduwa had higher percentages of young participants under the age of 20 than participants of other ages, and few participants over the age of 30 . The average age of all participants was 41.8 years.

When viewing the relationship between employment and participation rates, we found that in coastal areas with high employment rates, participation rates were low. However, participation rates were higher in inland areas with high unemployment. Because the workshops were held during the day on weekdays, it was difficult for employed people to participate. This has also been a problem for workshops conducted in Japan.

In each Community Workshop, challenges specific to that particular area were discussed. Table 3 shows the results compiled by the participants of a workshop held at a temple in Hikkaduwa. The primary risk for the area examined by this group is tsunamis. The participants identified countermeasures and assigned responsibility for the wide range of problems they found.

At the end of each Community Workshop, participants were surveyed about the workshop content. Valid responses were received from 2,940 participants. Fig. 10 shows the survey results. Basic information about the respondents is shown in Table 2. The survey results confirmed that the participants found the workshop interesting and acquired new knowledge about disaster reduction. These results show that the workshops are useful for raising awareness and educating people. However, more than $10 \%$ of respondents took a "neutral" position with regard to the "confirmation of evacuation routes" and the "benefit of discussions with neighborhood residents." Only about $30 \%$ of respondents indicated that they "strongly agreed" on these two items, a lower level of agreement than was indicated on the other survey items. A regional breakdown of these two items reveals that positive opinions were indicated by about $70 \%$ of respondents in both Neluwa and Welivitiya-Divithura (regarding the former) and in WelivitiyaDivithura and Ambalangoda (regarding the latter), lower than in the other DS-divisions. We reexamined the content of the instruction provided in these areas, but did not find any particular problems. We will need to pay attention to this finding in our followup activities. On questions regarding future activities, most respondents indicated that they would like to see them continue, giving us hope that they will be sustained in the future. The overall reactions about these community-level workshops were positive.

It bears mentioning that the participation of the district disaster 
Table 3 Sample Workshop Summary.

DS-division: Hikkaduwa, Venue: Kumarakanda-Kumara Maha Temple, Date: 10 November 2006

\begin{tabular}{|c|c|c|c|}
\hline No. & Problem & Solution & Responsible Authority \\
\hline 1 & $\begin{array}{l}\text { The drainage system near Kumarakanda } \\
\text { Visual Photo Centre is too narrow and } \\
\text { blocked by shrubs. }\end{array}$ & $\begin{array}{l}\text { Widen the drainage system. } \\
\text { Clean the drainage system. }\end{array}$ & Hikkaduwa Urban Council \\
\hline 2 & $\begin{array}{l}\text { Byways on either side of Kumara Kanda } \\
\text { main road do not have protective stone } \\
\text { barriers. Absence of a drainage system. }\end{array}$ & $\begin{array}{l}\text { Construct a protective stone barrier. } \\
\text { Construct a drainage system. }\end{array}$ & $\begin{array}{l}\text { Hikkaduwa Urban Council, } \\
\text { Coast Conservation Department }\end{array}$ \\
\hline 3 & $\begin{array}{l}\text { Point Karupa is situated in front of the } \\
\text { Cooperative Credit Society }\end{array}$ & Construct a protective stone barrier. & Coast Conservation Department \\
\hline 4 & $\begin{array}{l}\text { The main road in front of RJ Marine } \\
\text { Engine Workshop is very close to the sea }\end{array}$ & Construct a protective barrier. & Road Development Authority \\
\hline 5 & $\begin{array}{l}\text { Narrowing of the estuary near } \\
\text { Dodanduwa Bridge }\end{array}$ & Widen the estuary & Irrigation Department \\
\hline 6 & $\begin{array}{l}\text { Sanasa Jothi Road and Dodanduwa Road } \\
\text { are narrowing. Absence of a railway gate } \\
\text { at Dodanduwa Road. }\end{array}$ & $\begin{array}{l}\text { Widen roads. } \\
\text { Install a railway gate. }\end{array}$ & $\begin{array}{l}\text { Hikkaduwa Urban Council, } \\
\text { Railway Department }\end{array}$ \\
\hline
\end{tabular}

Note: This table was translated into English from Sinhalese.

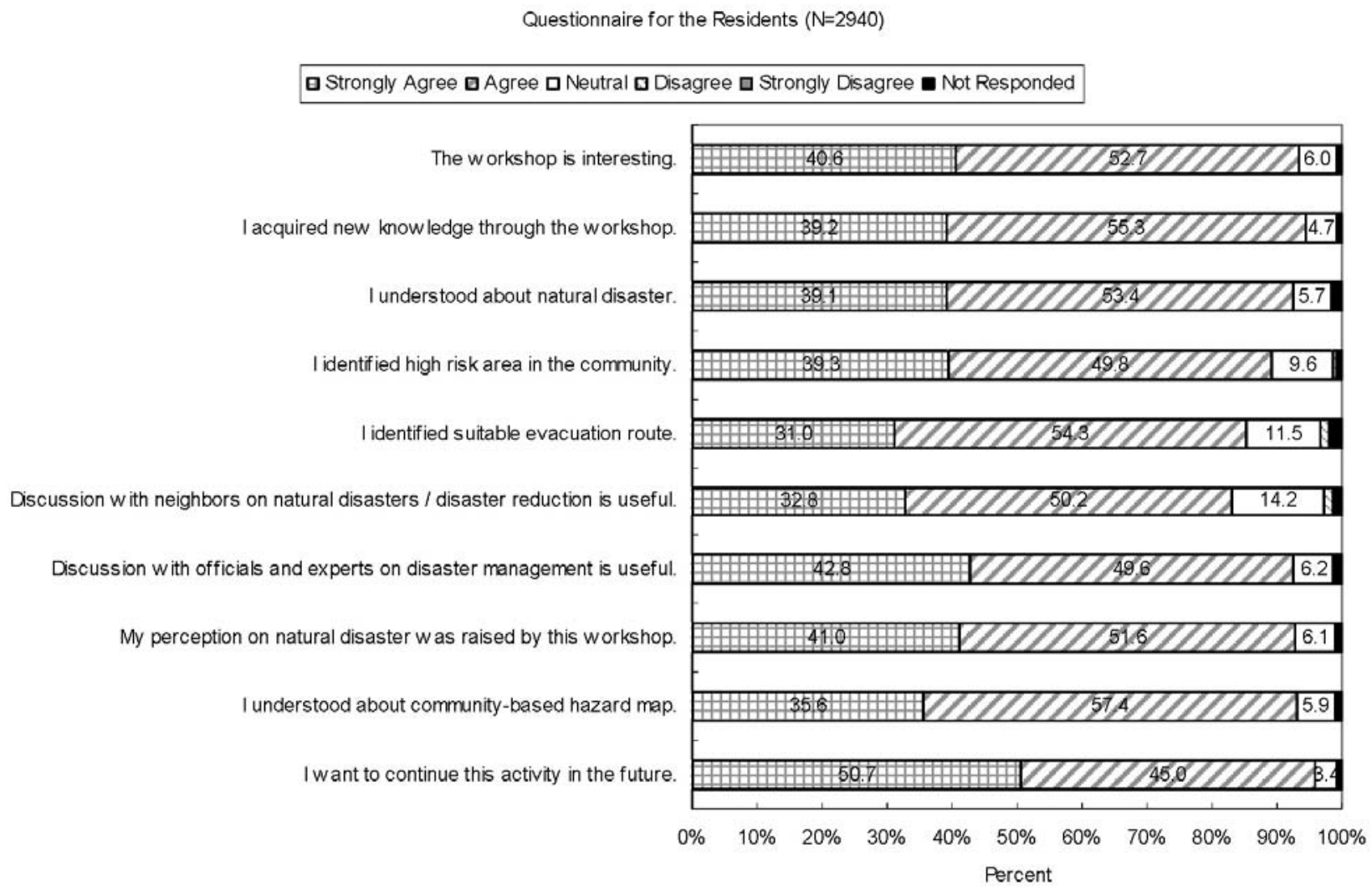

Fig. 10 Community Workshop Participant Survey Results.

management coordinator for Galle District in the Community Workshops and in providing guidance to residents promoted the creation of a structure for increasing the involvement of the Disaster Management Centre in community-based disaster reduction activities.

\subsection{Final Evaluation Session}

On March 30, 2007, 40 government officials from Galle District, which conducted the Community Workshops, gathered to hold a final evaluation session after the project had ended. The participants provided the following feedback. (1) This was the first time for local residents to participate in this kind of workshop. (2) 
It was useful to have many community leaders participate in the workshops. (3) Thus far, attention had only been paid to post-disaster response, but no efforts had been made to encourage residents think in advance about the kinds of disaster risks their communities face. (4) This program was very useful in terms of raising awareness and educating people about disaster reduction. (5) It was helpful in this case to have such activities launched from an external organization. Otherwise, the members of this community would never have come up with these kinds of disaster reduction activities on their own.

During the final evaluation session, discussions with the Galle District government regarding the future of disaster reduction education led to an agreement to hold at least one workshop in all 19 DS-divisions during the year after the project ends. These activities will be conducted entirely by the district government, without any involvement from outside organizations, including ours. Locally hired staff can observe these workshops and confirm the content that they cover. We hope that through this period, a shift will be made toward locally autonomous implementation of community-based disaster reduction activities.

\section{RESULTS OF ACTIVITIES AND DISCUSSIONS}

\subsection{District Level}

By conducting instructor training for district government officials, we were able to cultivate disaster reduction education leaders in local communities. These trainers then held as many as 102 workshops in their communities and gained a great deal of experience in educating and guiding residents. We hope that the continuation of such activities in the future will significantly improve the disaster reduction capacity of these communities. Also, the hazard maps that were created by local residents in each community can be used for a variety of disaster reduction efforts in the future.

As was seen in Thawalama and Neluwa, however, when government officials in positions of responsibility are transferred to new positions, there is not enough effort being made to ensure the adequate training of their successors. This is a major problem for programs such as this where continuity is of the utmost importance. Measures must therefore be developed to address this challenge.

\subsection{Community Level}

Under this project, we held workshops throughout Galle District, which were intended to raise the disaster awareness of local residents. We received positive feedback from workshop participants, with most residents having found the workshops to be interesting and having been satisfied with their content. Although this was the residents' first experience with the creation of hazard maps, all of the workshops were able to produce well-designed maps. We are pleased that participants expressed a desire for these activities to be continued in the future, but we know how difficult it is to sustain disaster reduction activities. The active involvement of relevant institutions is essential to the continuity of such activities.

When this kind of workshop is held in a community, many of the participants tend to be somewhat older. This project was unique in that it featured a good balance of participants from different age groups.

\subsection{Future Challenges}

The residents of communities with relatively low disaster risk have little motivation to think about damage countermeasures. Thus, workshops on hazard mapping are limited in their ability to raise disaster awareness in these areas. However, it is nonetheless possible that residents of such areas will encounter a disaster at some point when visiting a high-risk area. Thus, different methods from those used in this project need to be developed for educating those people about disaster reduction. For example, it may be effective in these areas to promote disaster education in schools.

Large-scale disasters of the magnitude of the 2004 Indian Ocean Tsunami occur infrequently in Sri Lanka. Even in a country like Japan, which is subject to frequent disasters of various kinds, there are regional differences in the frequency with which disasters occur, and the kinds of disasters that occur in some regions occur only at very long intervals. It is therefore more difficult to sustain awareness of disaster reduction in some communities. Given this, our next challenge in preparing for major disasters is to develop measures to ensure that awareness-raising efforts and disaster reduction education will be continuously implemented over the long-term, to the next generation and beyond.

\section{CONCLUSIONS}

This study analyzed and evaluated a community disaster reduction capacity improvement project that was conducted over the course of one year in Galle District in southern Sri Lanka, a community that was devastated by the 2004 Indian Ocean Tsunami and which has faced problems resulting from its vulnerability to natural disasters. The results of this study can be summarized as follows.

We conducted this project to raise awareness of natural disasters and promote disaster reduction education among the general populace using a community-based hazard mapping exercise.

This project provided a means of transferring methods of conducting community-based disaster reduction activities to Galle District. By conducting an instructor training program among district government officials, it also helped cultivate personnel who are capable of educating local residents. Through these efforts, we were able to establish a system of community-based disaster reduction activities.

A total of 102 Community Workshops (including the two pilot Community Workshops) were held, and these were attended by more than 3,000 local residents. The participants were highly interested in disaster reduction awareness activities using community-based hazard maps, and actively participated in the mapping process. We were able to confirm that the workshop participants understood the community-based disaster reduction lessons they were taught by conducting questionnaire surveys and listening to feedback at the end of the workshops.

We have taken measures to ensure that local residents will voluntarily continue these kinds of activities even beyond the end of this project, thereby ensuring the continuity of disaster reduction activities in this region.

Based on the results of this project, two important proposals can be made: (1) the workshop content should be interesting for the participants, and (2) attention should be paid to the independence of local people and supporters and our involvement should be min- 
imized. It would also be helpful to introduce elements aimed at improving community disaster reduction. Community workshops and school disaster education are most effective when used in parallel with one another, so efforts to implement them in tandem should be promoted.

Sri Lanka's disaster reduction structures were only first developed following the 2004 Indian Ocean Tsunami, and thus still largely consist of only general frameworks. We hope that the methods introduced in this project will be further modified by local residents so that the most suitable methods for the Sri Lankan context will become firmly established in that country.

\section{ACKNOWLEDGEMENTS}

This project was made possible by Grant Assistance for Japanese NGO Projects established by the Ministry of Foreign Affairs. The Japanese Embassy in Sri Lanka provided a great deal of useful advice and cooperation at every stage of project development, from planning to implementation. Cooperation on the District Workshop was provided by UNCRD-Kobe and UNV. Support was also provided by local expert instructors Prof. Kapila Dahanayake of Peradeniya University and Dr. Nimal Wijayaratna of Ruhuna University, and Japanese expert instructor Fumihiko Taniwa of the City of Kobe Fire Bureau. We are deeply grateful to all of those who were involved in this project.

\section{REFERENCES}

Disaster Management Centre, Ministry of Disaster Management and Human Rights, Government of Sri Lanka, 2005. Towards a safer Sri Lanka -A road map for disaster risk management.

Inaba, E., 2007. Promotion of safer urban area development and community leaders on disaster reduction, Journal of Japan Society for Natural Disaster Science, Vol.26, No.2, pp.108-113, (in Japanese).

JICA, 2006. Social development under the preparation against disaster, monthly JICA, November, pp.8-19, (in Japanese).

Kurita, T. Nakamura, A., Kodama, M. and Colombage, S., 2005. Examination of tsunami risk awareness in Sri Lanka, Journal of Social
Safety Science, Institute of Social Safety Science, , No.7, pp.315-323, (in Japanese).

Kurita, T., Nakamura, A. Kodama, M. and Colombage, S., 2006. Tsunami public awareness and the disaster management system of Sri Lanka, Disaster Reduction and Management, Vol. 15, No.1, pp. 92-110.

Maki, N., Kondo, T., Tamura, K., Hayashi, H., Topping, K., Tatsuki, S., Hasegawa, K., Horie, K., Bamba, M., Tanaka, S., Fukasawa, Y. and Yoshitomi, N., 2004. A comprehensive earthquake disaster reduction planning with stakeholders; Development of Marikina comprehensive earthquake disaster reduction program (CEDR) and action plan, Journal of Social Safety Science, Institute of Social Safety Science, No.6, pp.111-120, (in Japanese).

Miyamoto, H., 2007. Trainning of community leaders on disaster reduction in Kagawa Prefecture, Journal of Japan Society for Natural Disaster Science, Vol.26, No.2, pp.121-125, (in Japanese).

Nakagawa, K., 2007. Trainning program of community leaders on disaster reduction in Kochi Prefecture, Journal of Japan Society for Natural Disaster Science, Vol.26, No.2, pp.118-121, (in Japanese).

National Disaster Management Centre, Ministry of Resettlements and Disaster Relief Services, Government of Sri Lanka, 2004.Variation of main disasters for 1974 to 2004, http://www.ndmc.gov.lk/index.htm.

Otsubo, H., 2007. Training of community leaders on disaster reduction in Tokushima Prefecture, Journal of Japan Society for Natural Disaster Science, Vol.26, No.2, pp.138-144, (in Japanese).

Tabata, H., 2007. Promotion of community leaders on disaster reduction, Journal of Japan Society for Natural Disaster Science, Vol.26, No.2, pp.113-117, (in Japanese).

The Island newspaper, October 19, 2006, http://www.island.lk.

UNESCO, 2005 a. Assessment of capacity building requirements for an effective and durable tsunami warning and mitigation system in the Indian Ocean, Consolidated report for countries affected by the 26 December 2004 tsunami, IOC/INF-1219.

UNESCO, 2005 b. Expert missions to Indian Ocean countries to assess requirements and capacity for an effective and durable national tsunami warning and mitigation system, Mission Report No.25.

UNOCHA, 2003. Sri Lanka - Floods OCHA situation report No.1, http://www.reliefweb.int/rw/dbc.nsf. 